\title{
An Asset Protection Scheme for Banks Exposed to Troubled Loan Portfolios
}

\author{
Anders Grosen ${ }^{\mathrm{a}}$, Pernille Jessen ${ }^{\mathrm{a}}$, Thomas Kokholm ${ }^{\mathrm{a}}$ \\ ${ }^{a}$ Aarhus School of Business \\ Aarhus University \\ Fuglesangs Allé 4 \\ 8210 Aarhus $V$ \\ DENMARK
}

\begin{abstract}
We examine a specific portfolio credit derivative, an Asset Protection Scheme (APS), and its applicability as a tool to restore financial stability and reduce asymmetric information. As opposed to most governmental bailout packages implemented across the world recently, the APS can be a fair valued contract with an appropriate structure of incentives.

Within the structural credit risk modeling framework, we apply two alternative multivariate default risk models; the classical Gaussian Merton model and a model based on Normal Inverse Gaussian (NIG) processes. Exchanging the normal factors in the Gaussian model with NIG factors adds more flexibility to the distribution of asset returns while retaining a convenient correlation structure.

Using a unique data set on annual, farm level data from 1996 to 2009, we consider the Danish agricultural sector as a case study and price an APS on an agricultural loan portfolio. Moreover, we compute the economic capital for this loan portfolio with and without an APS.

Key words: Asset Protection Scheme, Bank regulation, Credit risk, Portfolio credit derivatives, Normal Inverse Gaussian, Asymmetric information

JEL Classification: G13, G21, G32, G38
\end{abstract}

*Contact: gro@asb.dk, peje@asb.dk, thko@asb.dk. 


\section{Contents}

1 Introduction 3

2 Asset Protection Scheme (APS) 6

2.1 Construction and Motivation ............... 6

2.2 The APS and Financial Stability . . . . . . . . . . . 7

3 Credit Risk and APS Valuation $\quad 9$

3.1 Gaussian Innovations in the Asset Returns . . . . . . . . . . . . . 9

3.2 Normal Inverse Gaussian Innovations in the Asset Returns . . . . 10

3.2.1 Simulation . . . . . . . . . . . . . . . 12

3.3 Pricing of an APS . . . . . . . . . . . . . . . 12

4 Estimation and Valuation 13

4.1 Data . . . . . . . . . . . . . . . . . 13

4.2 Estimation of Parameters in the Asset Value Dynamics . . . . . . 14

4.3 Valuation of the APS . . . . . . . . . . . . . . 16

5 Capital Requirements $\quad 17$

5.1 Economic Capital . . . . . . . . . . . . . . . . . . . . 17

5.2 Minimum Regulatory Capital . . . . . . . . . . . . . . . . . . . . 19

6 Conclusion $\quad 20$ 


\section{Introduction}

In the aftermath of the financial crisis, many banks are highly exposed to the credit risk of certain distressed sectors and fear severe losses which may threaten their survival. To cope with this increased uncertainty, the banks need more buffer capital. However, the informational asymmetries inherent in banking relationships suggest that urgent recapitalization may be prohibitively costly or impossible. Consequently, the market for borrowing and for raising new equity capital for banks may collapse and lead to a credit crunch for both banks and their borrowers.

In such an unfavorable situation, the government may wish to interfere if it considers the given sector "too big" or "too important" to fail. We suggest that any interference should fulfil at least one of the two following objectives. First, it should reestablish confidence in the banks' balance sheets and decrease asymmetric information, hereby easing the issuing of new equity capital. Second, it should release bank capital which should enable lending to financially healthy borrowers, helping these to invest and be innovative.

For this purpose, we analyze a particular portfolio credit derivative, the Asset Protection Scheme (APS), and provide a practical application of this instrument using the Danish agricultural sector as a case study. The APS was initially introduced by the regulatory authorities in the UK as a response to the financial crisis, and it is a type of credit derivative which intuitively can be considered as an insurance contract covering part of the default risk in a loan portfolio. A governmental insurance contract covering extreme market events can be a convenient political tool to meet the objectives stated above. An APS can be fairly priced and non-subsidiary as opposed to most governmental bailout packages implemented across the world recently.

More specifically, the APS has the cash flows as follows. If we consider an insurer who sells an APS to a bank, then the bank pays a fixed fee to the insurer on a regular basis in return for compensation in case the loan portfolio losses exceed a predefined threshold. If this threshold is exceeded, a given fraction of the subsequent losses remains the liability of the bank which thus retains financial motivation to service the individual loans in the portfolio even after the insurance contract has gone into effect.

The APS introduced above should be seen as a tool to overcome the problems arising from the informational asymmetries in banking relationships after a negative shock to the economy. These problems are serious as the core business of banks is to mitigate issues of asymmetric information between lenders and borrowers as pointed out by Diamond (1984) and others (see Bhattacharya and Thakor (1993) for a review). The consequences can be dramatic as illustrated by the collapse of the banking markets in the wake of the financial crisis. This collapse can be explained by the fact that equilibria in markets with asymmetric information are inherently unstable as initially described by Akerlof (1970). In 
such markets, even small changes in market conditions can have the consequence that the market disappears (or reappears). In this paper, the problems in raising new equity capital for banks after a negative shock to the economy is addressed. If banks cannot issue equity in economic downturns, it might lead to a severe contraction in the supply of credit. This problem is-as demonstrated in Repullo and Suarez (2008)-aggravated by the Basel II accord since capital requirements prescribed for credit risk increase during downturns.

Within the structural credit risk modeling framework introduced by Merton (1974), we consider two alternative multivariate default risk models. The first model, included as a benchmark, is the classical approach based on Gaussian innovations in the log asset returns. The second model seeks to capture extreme market risk; it allows for jumps and the log asset returns have Normal Inverse Gaussian innovations, see Barndorff-Nielsen (1997). Multivariate credit modeling using the Gaussian model by Merton (1974)-or variations of it-already proved itself insufficient in the early stages of the financial crisis since it failed to model realistic loss distributions. Exchanging the normal factors in the Gaussian model with NIG distributed factors adds more flexibility to the distributional properties of asset returns while retaining a convenient correlation structure. The NIG process has been successfully applied in finance, see, e.g., Rydberg (1997) for stock market modeling and Nicolato and Skovmand (2010) for interest rate modeling. The NIG distribution has been used for multivariate credit modeling in Kalemanova et al. (2007) who consider a one factor copula approach, but a multivariate structural NIG model has not previously been applied in the literature on credit risk. However, related to the approach of this paper, a multivariate model is proposed in a study by Luciano and Schoutens (2006) where the log asset returns are Variance Gamma distributed.

Katchova and Barry (2005) study credit risk of agricultural lending within the structural Merton model and estimate capital requirements for agricultural lenders under the Basel II framework. They show that these capital requirements vary substantially depending on the riskiness and homogeneity of the portfolio. However, Pederson and Zech (2009) find that the Merton model is inappropriate for the modeling of agricultural credit risk. The authors argue that the assumption of asset dynamics following geometric Brownian motions is not realistic.

Stokes and Brinch (2001) let the probability of default depend on the value of farmland. A significant part of farm assets consists of farmland: according to the US Department of Agriculture (2009), the average farm in the US in 2007 had approximately $90 \%$ of its assets tied up in farm real estate and machinery. In comparison, according to Statistics Denmark, ${ }^{1}$ the average farm in Denmark in 2007 had roughly $82 \%$ of its assets in farm real estate. Therefore, if the market for farm land experiences a sudden negative shock, we expect that this event

\footnotetext{
${ }^{1}$ www.statistikbanken.dk
} 

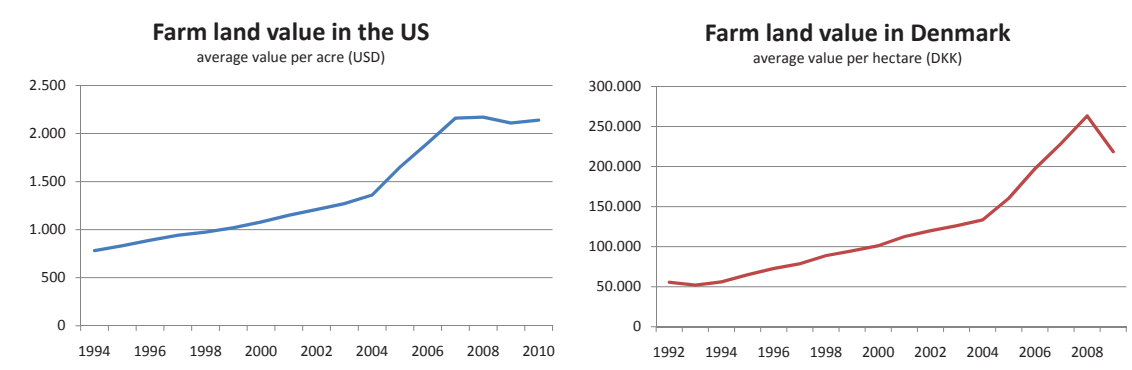

Source: USDA see http://usda.mannlib.cornell.edu

Source: Statistics Denmark see www.statistikbanken.dk

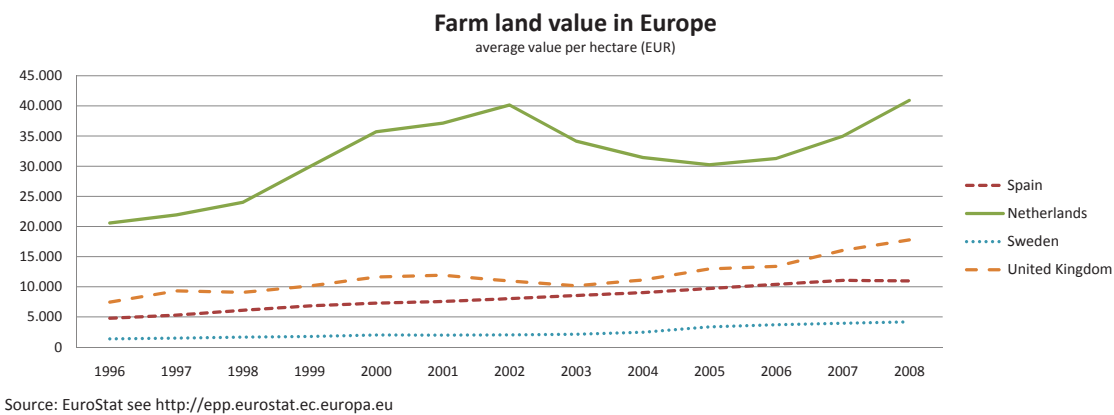

Figure 1: The development in average farmland prices for the US, Denmark, and a number of European countries.

will significantly affect the value of farm assets. Yan and Barry (2006) suggest, however, that the value of farmland is non-depreciable and that agricultural defaults may not necessarily lead to losses for the lender. Using data from the US Department of Agriculture on farm land values for the period from 1950 to 2002, the authors show that when the loan collateral is farmland, it is expected to cover the loan balance with relatively high probability in case of default. Even though this finding is historically meaningful, our current economic situation is very likely to lead to different results.

Figure 1 shows the development in land prices in the US, Denmark, and a number of European countries. For the US, UK, Netherlands, and Denmark, the graphs depict a steep increase in prices during the previous six years, and in Denmark this development has been followed by a sudden decrease. The figure indicates that some countries may currently experience an over-valuation of farmland and therefore may face future decreasing prices.

Sherrick et al. (2000) consider the valuation of credit risk in agricultural loans and estimate the cost of insuring against credit risk in pools of agricultural loans. Using an actuarial approach and contingent claim analysis, they find that the value of such insurance depends on the size of the pool, deductibles, timing, premiums, adverse selection, and under-writing standards. Furthermore, they show that insurance costs are highly sensitive to these factors for small pools but become relatively insensitive when the size of the pool grows.

Our numerical implementation of the APS valuation builds on a unique data 
set on Danish agricultural panel data. The Danish Agricultural Advisory Service (Landbrugsraadgivningen) has generously offered us annual, farm level data for the period from 1996 to 2009. We estimate a joint default risk model and price an APS based on a hypothetical loan portfolio via simulation using the two alternative models. Moreover, we compute the economic capital for this loan portfolio with and without an APS for the two models. Brief descriptive statistics offer intuition on the development in the sector during the past 14 years, the period of time where a price bubble seems to have emerged in farmland prices (see Danmarks Nationalbank (2009)).

The contribution to the financial literature on credit risk is the empirical analysis of a unique data set on agricultural loans. Moreover, we demonstrate how to apply a multivariate structural NIG model to credit risk. The contribution to the banking literature is the suggestion of how to use a specific credit derivative with a desirable structure of incentives to cope with asymmetric information problems in banking when market conditions are extreme. Finally, the paper contributes by suggesting how to address the serious problems concerning the financial side of the Danish agricultural sector-or any other particular, distressed sector experiencing similar problems.

\section{Asset Protection Scheme (APS)}

This section describes the APS and explains how it can be used as a fair valued tool by financial authorities.

\subsection{Construction and Motivation}

The APS seller provides the buyer with protection against credit losses incurred on a given portfolio when the losses exceed a specified "first loss" threshold $\alpha_{1}$ in return for a fee. If the first loss level is passed, the protection seller covers $\left(1-\alpha_{2}\right)$ of the following portfolio loss while the buyer still bears the residual loss, $\alpha_{2}$. Figure 2 shows a stylized version of the APS structure. For a description of the properties and terms of the APS contracts implemented in the UK, see The Royal Bank of Scotland Group (RBS) (2009), HM Treasury (2009a), and HM Treasury (2009b).

The covered assets remain on the balance sheet of the protection buyer who economically and legally still owns the assets. The first loss threshold $\alpha_{1}$ serves as a deductible, which is a common feature of insurance contracts. After the first loss threshold is exceeded, the protection buyer still covers a fraction $\alpha_{2}$ of the further losses and thus retains an appropriate structure of incentives to continue the diligent management of the loan portfolio. Since the APS slices portfolio credit risk into tranches similar to a Collateralized Debt Obligation (CDO), we use the corresponding terminology. Figure 3 shows the tranche loss as a function of the number of defaults in the underlying portfolio. 


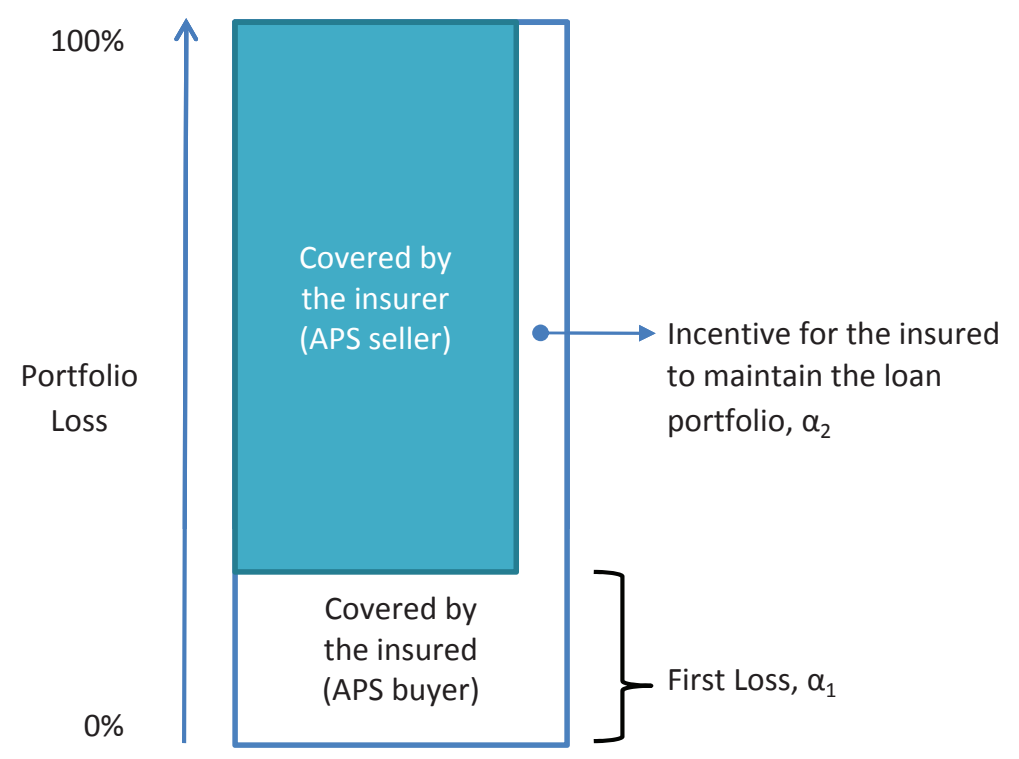

Figure 2: The figure shows how the APS covers extreme losses in a loan portfolio. The APS takes effect if the portfolio loss exceeds a given first loss threshold $\alpha_{1}$. In this case, the bank still covers a fraction $\alpha_{2}$ of the following losses and thus retains an incentive to maintain the portfolio.

Generally, the covered assets can be of any asset class; residential mortgages, consumer finance, bonds, loans, structured products, or derivatives. In case of a governmentally issued APS, the underlying portfolio would typically represent a certain distressed sector related to the current financial climate.

\subsection{The APS and Financial Stability}

In the following, we describe circumstances under which financial authorities can apply the APS as a tool to enhance financial stability. In particular, we consider two situations where the APS can be useful.

The first case was illustrated during the financial crisis by the collapse of banks' funding in the money market. After a major negative shock to the economy, the market for bank lending may experience an increase in asymmetric information and face undesirable consequences. Banks with lower quality loan portfolios are more interested in issuing equity than banks with higher quality loan portfolios, and this may result in prices for new equity being prohibitively high. Consequently, the market for bank equity capital may experience large price discounts-or even a market collapse-when increases in banks' buffer capital and access to the money market funding are most needed. An APS can help free up liquidity in the secondary markets by substantially reducing the tail risk of losses of the insured institution, hereby allowing it to stabilize its capital base and in an orderly manner decrease leverage over time. 


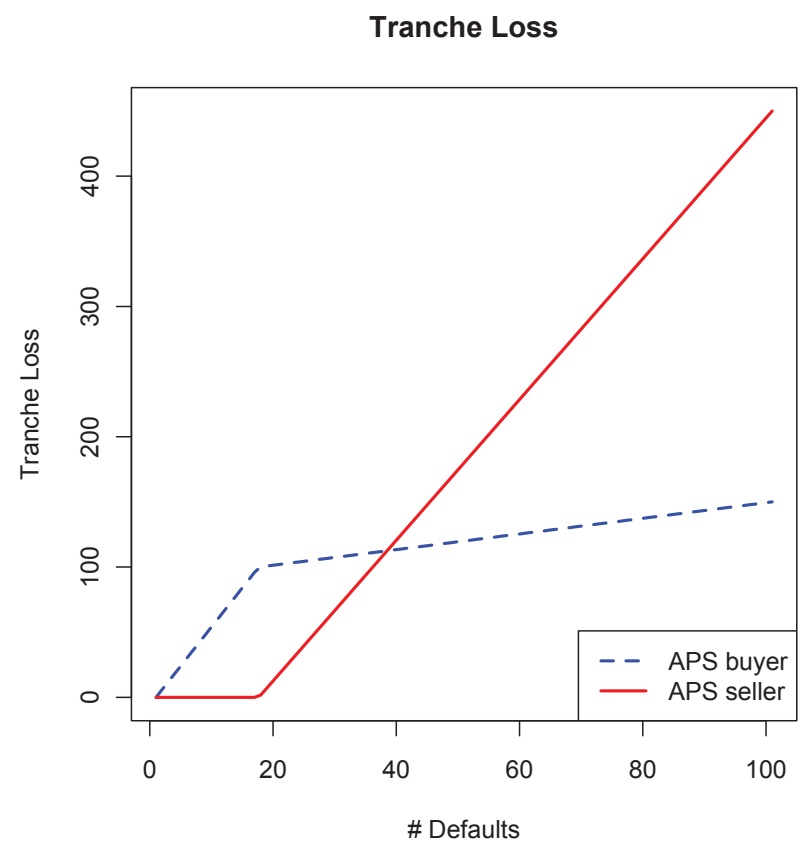

Figure 3: The figure shows the tranche loss as a function of number of defaults in an underlying portfolio of size EUR 1,000 with 100 equally weighted loans and a recovery rate of $40 \%$. The APS has the parameters $\alpha_{1}=\alpha_{2}=10 \%$.

In this situation, the APS manages the risk of the taxpayers: if the troubled institutions are considered "too important" or "too big" to fail, the government may be forced to interfere with the industry when it is threatened by extreme market events. However, when the government is the seller of the APS, the government collects compensation for this (politically implicit) guarantee in the form of fee payments. From the perspective of the taxpayer, the government should prefer the formal insurance contract with this compensation instead of the implicit guarantee.

The second case where the APS can be useful concerns the situation when a governmental authority has taken over a troubled bank. Normally the authority will try to sell the troubled loan portfolio to another, well-functioning bank, however, due to the asymmetric information in banking relationships, it might be difficult to find a bank willing to take over the troubled loan portfolio. In order to ease this situation, the government can attach an APS as a state guarantee to the troubled portfolio in order to mitigate the asymmetric information concerns. Both the borrowers in the troubled loan portfolio and the government can benefit from such contract. First, transferring the loan portfolio secures a banking relationship for the troubled debtors. Lack of a personal banking relationship may have severe negative effects on already troubled loans. Second, the government lacks banking expertise and operational systems, and therefore we expect that 
the government has a strong interest in selling the activities of the troubled bank.

In Denmark, for example, the Financial Stability company ${ }^{2}$ is part of an agreement between the Danish state and the Danish financial sector. The company was established in October 2008 as a reaction to the financial crisis, and it handles troubled banks and seeks to support the banking industry with various state guarantees. However, an establishment like Financial Stability is a liquidation company and does not necessarily have the banking expertise to maintain the loan portfolio of a troubled bank.

In the following, we consider a practical application of the first case when we perform a numerical example based on the Danish agricultural sector.

\section{Credit Risk and APS Valuation}

Consider a filtered probability space $\left(\Omega, \mathcal{F},\left\{\mathcal{F}_{t}\right\}_{t \geq 0}, \mathbb{P}\right)$ where the asset value processes $A_{t}^{i}$ for $i=1, \ldots, M$ are adapted to the filtration $\left\{\mathcal{F}_{t}\right\}_{t \geq 0}$. Let $K^{1}, \ldots, K^{M}$ denote the total principal value of debt of company 1 to $M$ at time zero. We model the asset values as

$$
A_{t}^{i}=A_{0}^{i} \exp \left\{X_{t}^{i}\right\}
$$

where $X_{t}^{i}$ is a stochastic process.

For a given tenor structure

$$
0=T_{0}<T_{1}<\ldots<T_{n}<\ldots
$$

we define the default time of company $i$ as

$$
\tau^{i}=\inf \left\{t \in\left\{T_{1}, \ldots, T_{n}, \ldots\right\} \mid A_{t}^{i}<K^{i}\right\}
$$

In this framework the defaults are modeled via the log asset returns $X_{t}^{i} \mathrm{~s}$, and we consider two alternative specifications: correlated Gaussian innovations and correlated Normal Inverse Gaussian innovations.

\subsection{Gaussian Innovations in the Asset Returns}

Assume that the value of the assets of a company follows a geometric Brownian motion under the physical measure. At time $t$ the $i$ 'th company's asset value is

$$
A_{t}^{i}=A_{0}^{i} \exp \left\{\mu_{i} t+\sigma_{i} W_{t}^{i}\right\}
$$

where $\mu_{i}$ is the average annual $\log$ return, $\sigma_{i}$ is the instantaneous volatility, and $W_{t}^{i}$ is a Wiener process driving the development. $W_{t}^{i}$ is allowed to correlate with the Wiener process $W_{t}^{j}$ of company $j$ with parameter $\rho^{i, j}$ such that $d W_{t}^{j} d W_{t}^{i}=\rho^{i, j} d t$.

\footnotetext{
${ }^{2}$ http://www.finansielstabilitet.dk/en/
} 
The risk neutral dynamics of the asset values is found by setting the instantaneous rate of return equal to the risk free rate. For company $i$ at time $t$, the risk neutral dynamics is

$$
A_{t}^{i}=A_{0}^{i} \exp \left\{\left(r-\sigma_{i}^{2} / 2\right) t+\sigma_{i} W_{t}^{i}\right\} .
$$

In the estimation related to our case study, the parameters $\mu_{i}, \sigma_{i}$, and $\rho^{i, j}$ for $i, j=1, \ldots, M$ are estimated from historical data on farm asset values, see Section 4.2 .

\subsection{Normal Inverse Gaussian Innovations in the Asset Returns}

In this section, we allow for more flexibility in the log asset values by letting them have normal inverse Gaussian dynamics. Correlated NIG processes are generated by time-changing/subordinating correlated Brownian motions with an Inverse Gaussian (IG) process

$$
X_{t}^{i}=\mu_{i} I_{t}+\delta_{i} W_{I_{t}}^{i}
$$

where the Brownian parts $W_{t}^{i}$ s are correlated but independent of the common IG subordinator $I_{t}$. For normalization reasons, we consider an IG time-change with $\mathbb{E}\left[I_{t}\right]=t$, which leaves one parameter $\kappa$ for the variance. Since $I_{t}$ is positive, we describe it using the moment generating function

$$
\mathbb{E}\left[e^{u I_{t}}\right]=e^{t l(u)} \quad \forall u \in \mathbb{R},
$$

where (see Cont and Tankov (2004))

$$
l(u)=\frac{1}{\kappa}(1-\sqrt{1-2 \kappa u}) .
$$

From the moment generating function, the central moments of the time-change can be found by differentiation, and they are reported in Table 1.

Table 1: Central moments of the IG process $I_{t}$ with parameter $\kappa$.

\begin{tabular}{ll}
\hline $\mathbb{E} I_{t}$ & $t$ \\
$\mathbb{E}\left(I_{t}-t\right)^{2}$ & $t \kappa$ \\
$\mathbb{E}\left(I_{t}-t\right)^{3}$ & $3 t \kappa^{2}$ \\
$\mathbb{E}\left(I_{t}-t\right)^{4}$ & $15 t \kappa^{3}+3 t^{2} \kappa^{2}$ \\
\hline
\end{tabular}

The characteristic function of a Lévy process $X_{t}$ has the form

$$
\mathbb{E}\left[e^{\mathrm{i} u X_{t}}\right]=e^{t \Psi(u)},
$$


where $\Psi(u)$ is the characteristic exponent. For an NIG process, this is given by

$$
\Psi(u)=\frac{1}{\kappa}\left(1-\sqrt{1-2 \mathrm{i} \mu u \kappa+u^{2} \delta^{2} \kappa}\right),
$$

which can be used to find the central moments of the NIG process. Table 2 reports the central moments of both the Gaussian and the NIG process.

Table 2: Central moments of the Gaussian process with parameters $\mu, \sigma$ and the Normal Inverse Gaussian process with parameters $\mu, \delta, \kappa$.

\begin{tabular}{lll}
\hline & Gaussian & NIG \\
\hline $\mathbb{E} X_{t}$ & $\mu t$ & $\mu t$ \\
$\mathbb{E}\left(X_{t}-\mu t\right)^{2}$ & $\sigma^{2} t$ & $\delta^{2} t+\mu^{2} \kappa t$ \\
$\mathbb{E}\left(X_{t}-\mu t\right)^{3}$ & 0 & $3 \delta^{2} \mu \kappa t+3 \mu^{3} \kappa^{2} t$ \\
$\mathbb{E}\left(X_{t}-\mu t\right)^{4}$ & $3 \sigma^{4} t^{2}$ & $3 \delta^{4} \kappa t+15 \mu^{4} \kappa^{3} t+18 \delta^{2} \mu^{2} \kappa^{2} t+3\left(\delta^{2} t+\mu^{2} \kappa t\right)^{2}$ \\
\hline
\end{tabular}

Assume that under the physical measure the asset value follows an exponential Lévy process

$$
A_{t}^{i}=A_{0}^{i} \exp \left\{X_{t}^{i}\right\}
$$

where $X_{t}^{i}$ is an NIG process with parameters $\delta_{i}, \mu_{i}, \kappa$. In general, the process defined in (11) will not be a martingale. We specify the dynamics of the asset value under an equivalent martingale measure by introducing a mean correcting drift $m_{i}$. The asset value is then

$$
A_{t}^{i}=A_{0}^{i} \exp \left\{m_{i} t+X_{t}^{i}\right\}
$$

where the martingale condition imposes that (see Raible (2000))

$$
m^{i}=r-\Psi^{i}(-\mathrm{i}) .
$$

Denote the correlation between the Brownian motions $W_{t}^{i}$ and $W_{t}^{j}$ by $\rho_{\text {Brown }}^{i, j}$. Then the correlation between $\log$ asset returns of company $i$ and $j$ can be computed by conditioning on $I_{t}$

$$
\rho^{i, j}=\frac{\delta_{i} \delta_{j} \rho_{\text {Brown }}^{i, j}+\mu_{i} \mu_{j} \kappa}{\sqrt{\delta_{i}^{2}+\mu_{i}^{2} \kappa} \sqrt{\delta_{j}^{2}+\mu_{j}^{2} \kappa}} .
$$

In the estimation related to our case study, the model parameters are estimated by matching the model moments in Table 2 to historical moments of the return data on individual farmers, see Section 4.2. 


\subsubsection{Simulation}

Inspection of equation (6) reveals the two-step recipe for simulating correlated NIG processes. First, we simulate IG distributed increments with mean $t_{j}-t_{j-1}$ and variance $\left(t_{j}-t_{j-1}\right) \kappa$ of the common subordinator $I_{t}$ and denote these increments by

$$
\Delta I_{t_{j}}=I_{t_{j}}-I_{t_{j-1}}
$$

Second, we simulate the log asset returns with

$$
\log A_{t_{j}}^{i}=\log A_{t_{j-1}}^{i}+m_{i}\left(t_{j}-t_{j-1}\right)+\mu_{i} \Delta I_{t_{j}}+\delta_{i} \sqrt{\Delta I_{t_{j}}} Z^{i}
$$

where the $Z^{i}$ s are drawn from a multivariate standard normal distribution with covariance matrix entries $\rho_{\text {Brown }}^{i, j}$.

\subsection{Pricing of an $A P S$}

Similar to a synthetic CDO tranche, an APS is a swap contract. It has the value of the expected present value of its cash flows; the APS seller receives periodic payments from the APS buyer (premium leg) and makes contingent payments to the buyer if defaults exceed the first loss threshold (protection leg). From the perspective of the buyer, the value of the APS is the difference between the expected present value of the protection leg and the expected present value of the premium leg.

Typically, the debt in company $i$ consists of a mortgage and a loan in the bank

$$
K^{i}=K^{i, M o r t}+K^{i, B a n k}
$$

where the mortgage lender has higher seniority. The bank thus holds the more risky part of the debt, and the total principal value in the bank portfolio is

$$
F=\sum_{i=1}^{M} K^{i, B a n k}
$$

Then the loss process in the bank portfolio is

$$
L_{t}=\sum_{i=1}^{M} \min \left\{K^{i}-A_{\tau^{i}}^{i}, K^{i, \text { Bank }}\right\} 1_{\left\{\tau^{i} \leq t\right\}},
$$

since each defaulted company, indicated by $1_{\left\{\tau^{i} \leq t\right\}}$, has the loss of either the full bank loan $K^{i, B a n k}$ or the principal value of the debt less the asset value-whatever amount is the smallest.

We consider an APS with annual premium payments, first loss threshold $\alpha_{1}$, and an incentive-percentage $\alpha_{2}$ (see Figure 2). The loss in the APS at time $t$ is given by

$$
L_{t}^{A P S}=\max \left\{L_{t}-\alpha_{1} F, 0\right\}\left(1-\alpha_{2}\right)
$$


since the APS only experiences loss if $L_{t}>\alpha_{1} F$. The present value of the protection payments for an APS with maturity $T_{n}$ is

$$
\pi^{\text {Prot }}=\mathbb{E}\left[\sum_{j=1}^{n} B\left(0, T_{j}\right)\left(L_{T_{j}}^{A P S}-L_{T_{j-1}}^{A P S}\right)\right]
$$

where $B\left(0, T_{j}\right)$ is the discount factor for the maturity $T_{j}$. The present value of the premiums equals

$$
\pi^{\text {Prem }}=\mathbb{E}\left[\sum_{j=1}^{n} B\left(0, T_{j}\right) s^{A P S}\left(F\left(1-\alpha_{1}\right)\left(1-\alpha_{2}\right)-L_{T_{j}}^{A P S}\right)\right]
$$

where the total value covered by the APS is $F\left(1-\alpha_{1}\right)\left(1-\alpha_{2}\right)$. The fair spread $s^{A P S}$ that makes the initial value of the contract zero can be found by equating (21) and (22), and it is given by

$$
s^{A P S}=\frac{\pi^{\text {Prot }}}{\mathbb{E}\left[\sum_{j=1}^{n} B\left(0, T_{j}\right)\left(F\left(1-\alpha_{1}\right)\left(1-\alpha_{2}\right)-L_{T_{j}}^{A P S}\right)\right]} .
$$

\section{Estimation and Valuation}

In this section, we use our data set and estimate the real world dynamics of the farm asset values as described in (4) and (11) for our two model specifications. From these dynamics, we derive the risk-neutral dynamics in (5) and (12) and price an APS on our agricultural loan portfolio via simulation using the two alternative models.

\subsection{Data}

Our numerical implementation of the APS valuation builds on a unique data set on Danish agricultural panel data provided by the Danish Agricultural Advisory Service (Landbrugsraadgivningen). The data set holds annual, farm level observations for the period from 1996 to 2009 and has detailed information on the value of assets of the individual farmer, amounts and types of debt, value of farmland, and more. We let the agricultural loan portfolio consist of the farms for which we have data for all 14 years. It amounts to 208 farms, and in 2009 the bank portfolio has a total principal value of $F=702,723,413$ DKK.

Figure 4 gives the development in average asset value, debt, and debt ratio over the period 1996 to 2009. The top graph in the figure shows the development in the average asset values and debt. We see that both quantities have increased significantly during the period but that the mean asset values have decreased since 2008 due to the decrease in farmland prices. The middle graph illustrates the average debt ratio defined as the total debt to asset values. We see that the 

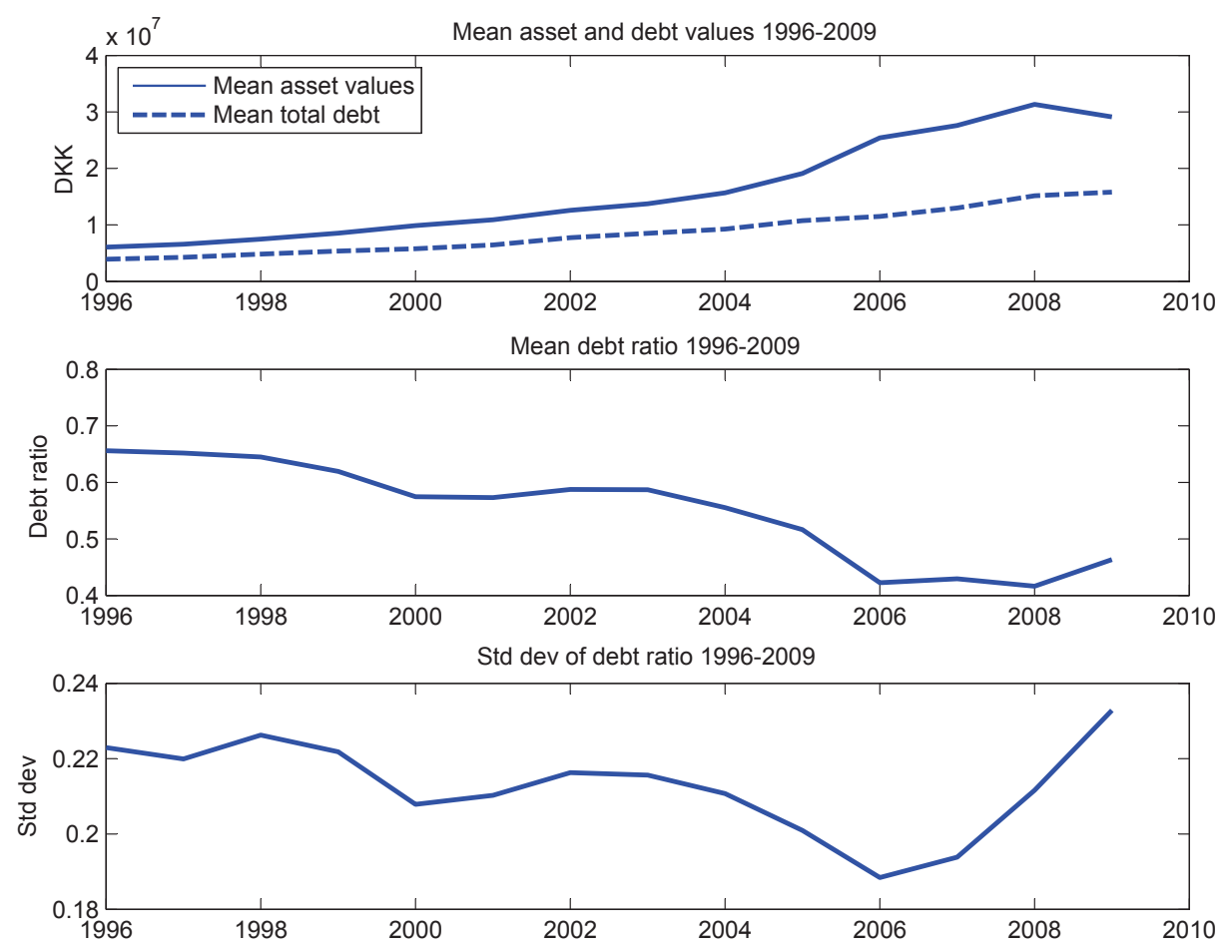

Figure 4: The figure shows the development in average asset value, debt, and debt ratio.

increasing asset values during 1996 to 2008 have caused a decreasing debt ratio, but since 2008 the debt ratio has gone up as a consequence of the decreased asset values. The bottom graph shows the standard deviation of the debt ratios for each year across farmers. We observe that the homogeneity in terms of debt ratio was high in 2006 but has decreased significantly since then. We interpret this result as a consequence of the falling land prices. While many farmers are still financially healthy, many farmers are now close to default, and thus the dispersion of the rates of solvency of farmers has become larger.

\subsection{Estimation of Parameters in the Asset Value Dynamics}

Estimation of the parameters in the two models is performed by matching the model moments to the empirical moments. Table 3 reports the average of the estimated annual return, standard deviation, skewness, and excess kurtosis 
defined by

$$
\begin{aligned}
\mu_{i} & =\mathbb{E} X^{i} \\
\sigma_{i} & =\sqrt{\mathbb{E}\left(X^{i}-\mu_{i}\right)^{2}} \\
s_{i} & =\frac{\mathbb{E}\left(X^{i}-\mu_{i}\right)^{3}}{\sigma_{i}^{3}} \\
k_{i} & =\frac{\mathbb{E}\left(X^{i}-\mu_{i}\right)^{4}}{\sigma_{i}^{4}}-3,
\end{aligned}
$$

where $X^{i}$ is the annual log asset return of farm $i$.

Table 3: The average across farms of the annual return, standard deviation, skewness, and excess kurtosis.

\begin{tabular}{cc}
\hline$\tilde{\mu}$ & 0.1120 \\
$\tilde{\sigma}$ & 0.1681 \\
$\tilde{s}$ & 0.7173 \\
$\tilde{k}$ & 1.6590 \\
\hline
\end{tabular}

For the Gaussian model, the first two moments can be matched precisely but skewness and excess kurtosis equal zero. Only the individual volatilities $\sigma_{i}$ s are important for valuation, but for risk management purposes, the first moment also matters. The pairwise correlations are all set equal, i.e., $\rho^{i, j}=\rho$ for $i, j=1, . ., M$ where $i \neq j$, and estimated as the average of the pairwise correlations, $\hat{\rho}=0.2146$.

In order to match higher moments of the log asset returns data, we consider the NIG framework. In the multivariate NIG model, the two free parameters $\mu_{i}$ and $\delta_{i}$ for each name and the common parameter $\kappa$ are estimated by minimizing the objective function

$$
\sum_{i=1}^{M} w_{1}\left(\tilde{\mu}_{i}-\mu_{i}\right)^{2}+w_{2}\left(\tilde{\sigma}_{i}-\sigma_{i}\right)^{2}+w_{3}\left(\tilde{s}_{i}-s_{i}\right)^{2}+w_{4}\left(\tilde{k}_{i}-k_{i}\right)^{2}
$$

where $w_{1}, . ., w_{4}$ are the weights given by (see Bartlett (1950))

$$
w_{n}=1-\frac{n}{5}
$$

The optimal value of the common parameter is $\hat{\kappa}=0.4286$ while the average values of the two free parameters are $\hat{\mu}=0.0594$ and $\hat{\delta}=0.1317$. The correlation between the Brownian components $\rho_{\text {Brown }}^{i, j}$ is found by inverting equation (14) for a fixed pairwise correlation equal to $\hat{\rho}=0.2146$. 


\subsection{Valuation of the APS}

We estimate the parameters in the two models from the data set and price a hypothetical APS with $\alpha_{1}=0.1, \alpha_{2}=0.1$, maturity $T=5$ years, and annual premium payments via simulation of $1,000,000$ sample paths of the two models. The risk-free rate of return is set constant and equal to $3 \%$. This assumption can be relaxed but one has to bear in mind that the driving process for the interest rate should be of the same type as the driving process in the firm assets, see, e.g., Cox et al. (1985) in the Gaussian case and Nicolato and Skovmand (2010) in the NIG case.

Based on the data, we compute the spreads in the two models to

$$
\begin{aligned}
& s_{\text {Gaussian }}^{A P S}=59 \quad b p \\
& s_{N I G}^{A P S}=41 \quad b p .
\end{aligned}
$$

The price for the Gaussian model is higher than for the NIG case since the NIG model is able to match the positive skewness of the empirical distribution of the asset value returns. This skewness results in a lower individual probability of default which infers a lower price of the APS.

If the value of farmland is experiencing a price bubble burst, it is relevant to consider scenarios where farm asset values decrease. Therefore, we price the APS on the agricultural loan portfolio where the asset values have decreased $10 \%$ and $30 \%$ respectively. Based on these decreases and all other things equal, the fair spreads are reported in Table 4 together with the spreads computed from the 2009 data $(0 \%)$.

Table 4: Based on a decrease in asset values of $10 \%$ to $30 \%$, the table shows the fair APS spreads in the two model specifications.

\begin{tabular}{lrr}
\hline Model & Gaussian & NIG \\
\hline $0 \%$ & $59 \mathrm{bp}$ & $41 \mathrm{bp}$ \\
$10 \%$ & $144 \mathrm{bp}$ & $111 \mathrm{bp}$ \\
$30 \%$ & $770 \mathrm{bp}$ & $718 \mathrm{bp}$ \\
\hline
\end{tabular}

We observe in Table 4 that as expected the spreads are increasing for decreasing asset values. Moreover, this increase is not linear because-when using the option terminology - the "option to default" becomes closer to being in the money as the asset values fall. The prices for the Gaussian model are once again higher than for the NIG case since the NIG model matches the positive skewness of the realized asset value returns. However, this effect becomes relatively smaller when the asset values decrease. 


\section{Capital Requirements}

This section considers the capital requirements for a hypothetical bank holding the given agricultural loan portfolio, before and after the bank enters the APS. The capital requirements of a financial institution have great impact on its performance since it is expensive to hold more capital than necessary. We consider the economic capital of the bank and comment on the minimum regulatory capital requirements in this context.

\subsection{Economic Capital}

Economic capital is the risk capital that ensures the technical solvency of a bank with a given probability over a given time horizon. The bank computes the economic capital under the physical measure typically with a Value at Risk (VaR) method (see Jorion (1997)).

McNeil et al. (2005) describe the economic capital as follows. The bank is conservatively capitalized over a given time period $[t, t+\Delta]$ if it holds equity $E$ for which it with a "high" probability $\beta$ holds that

$$
\mathbb{P}\left(\Delta L_{t+\Delta}-\mathbb{E}\left[\Delta L_{t+\Delta}\right]<E\right) \geq \beta,
$$

where $\Delta L_{t+\Delta}=L_{t+\Delta}-L_{t}$ is the loss in the loan portfolio over the given period of time. When the APS is included in the portfolio, we consider the premium payments as "losses" and add them to the total loss. The premium payments are computed from the spreads reported in the first row of Table 4.

The economic capital (EC) is defined as the amount of capital $E$ that makes the inequality in (30) binding. Hence

$$
\begin{aligned}
E C & =\operatorname{VaR}_{\beta}\left(\Delta L_{t+\Delta}\right)-\mathbb{E}\left[\Delta L_{t+\Delta}\right] \\
& =\operatorname{VaR}_{\beta}\left(\Delta L_{t+\Delta}-\mathbb{E}\left[\Delta L_{t+\Delta}\right]\right),
\end{aligned}
$$

where $V_{a} R_{\beta}$ is the $\beta$-quantile of the loss distribution. The economic capital is then considered sufficient to limit the probability of technical insolvency to $(1-\beta)$ over the given time period $[t, t+\Delta]$.

Equation (31) computes the contribution to the total economic capital from the loan portfolio. In general this will overestimate the required economic capital since it does not take into account the diversification effects from adding the loan portfolio to the bank assets. For a fully integrated model of economic capital see, e.g., McNeil et al. (2008).

Based on 1,000,000 sample paths, Figure 5 shows the loss distributions on a horizon of 5 years for both the original loan portfolio (top) and for the portfolio with an APS (bottom). The principal value of the loan portfolio amounts to $F=702,723,413$ DKK. The left side of the figure refers to the case where asset values follow a multivariate geometric Brownian motion, and the right side shows the NIG case. For the portfolio without the APS, we observe that the loss 
Gaussian
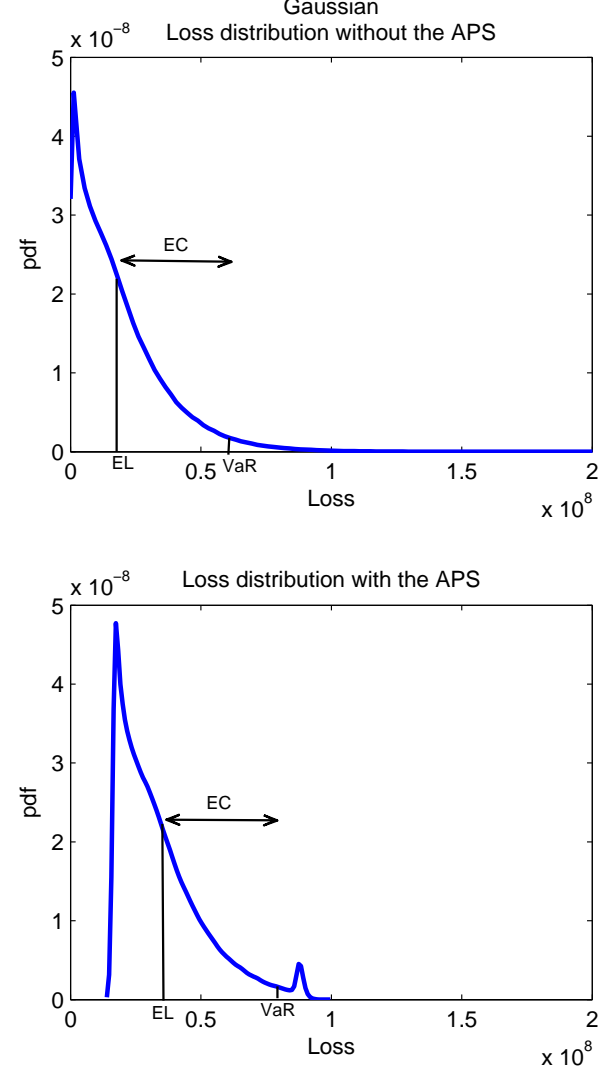
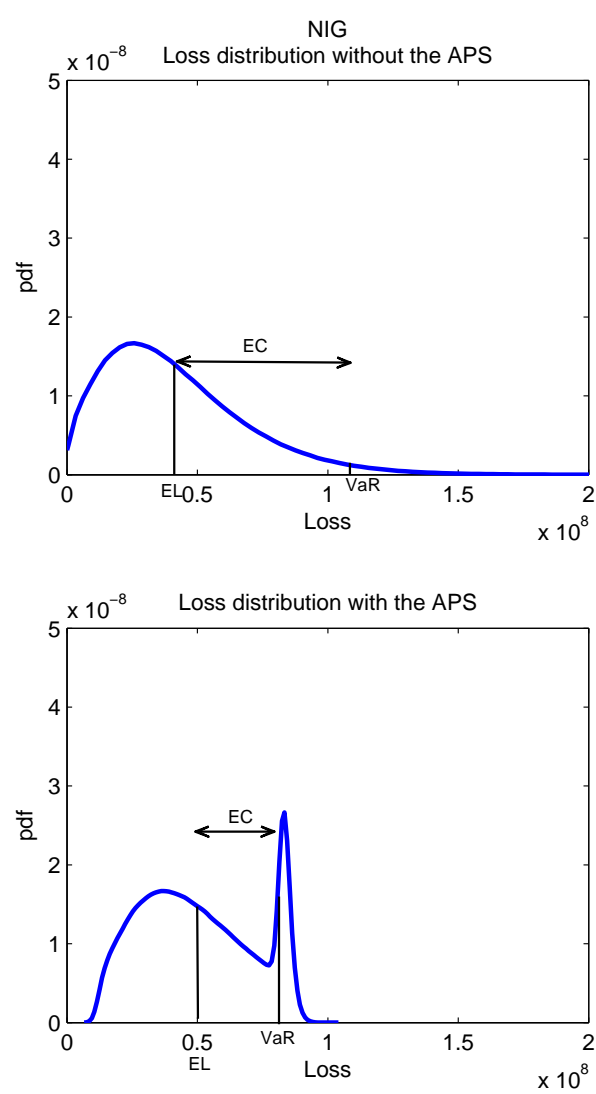

Figure 5: Estimated density functions for the losses on a horizon of 5 years for the Gaussian and the NIG model with and without the APS. The VaRs are computed as the $97.5 \%$ quantiles of the loss distributions.

distribution has a much heavier right tail for the NIG model than the Gaussian case, resulting in a much higher VaR and expected loss. For the portfolio with the APS, we observe that the loss distributions have two peaks. The first peak corresponds to the losses in the retained equity tranche, i.e., the portfolio loss from zero to $\alpha_{1} F$. The second peak arises because the losses above the threshold level are compressed due to the fraction $\alpha_{2}$ retained by the APS buyer.

In the figure, we indicate the expected losses and VaRs reported in Table 5 from which the economic capital numbers are computed. In the Gaussian model, the economic capitals are almost identical with or without the APS. Ignoring the premiums paid for entering the APS, the expected loss is lower when the APS is included while the VaRs are identical because the probability of exceeding the threshold is lower than $2.5 \%$. Since the premiums only shift the loss distribution to the right, we observe the counter-intuitive result that the economic capital is slightly higher in this case, an increase of 201,000 DKK or $0.45 \%$. In the 
NIG model, on the other hand, the probability of exceeding the loss threshold is greater than $2.5 \%$, and therefore the economic capital is reduced significantly when the portfolio includes the APS, a reduction of $31,531,000$ DKK or $47.42 \%$.

Table 5: The Expected Loss (EL), Economic Capital (EC), and the 97.5\% quantile of the loss distributions. The face value of the portfolio is $F=702,723,413 \mathrm{DKK}$, and the values in the table are in DKK.

\begin{tabular}{lrr}
\hline & Gaussian & NIG \\
\hline Without APS & & \\
EL & $18,047,000$ & $41,509,000$ \\
Quantile (0.975) & $62,264,000$ & $108,000,000$ \\
EC & $44,217,000$ & $66,495,000$ \\
EC/F & $6.3 \%$ & $9.5 \%$ \\
\hline With APS & & \\
EL & $34,637,000$ & $50,363,000$ \\
Quantile (0.975) & $79,055,000$ & $85,327,000$ \\
EC & $44,418,000$ & $34,964,000$ \\
EC/F & $6.3 \%$ & $5.0 \%$ \\
\hline
\end{tabular}

Inspection of Figure 5 indicates that the APS should be priced higher for the NIG model contradicting the actual prices computed in Section 4.3. This disparity occurs because the prices are computed under the risk-neutral measure while the loss distributions used for risk management purposes are estimated under the physical measure. As described in Section 4.2, the parameters are estimated by minimizing the objective function in (28) which is a weighted sum of the squared moment differences. As a result the annual expected log returns $\hat{\mu}_{i}$ s turns out quite differently in the NIG case (average of 0.0594 ) than those of the Gaussian model where the empirical log returns are matched precisely (average of 0.1120). This difference in the expected return is apparent under the physical measure while unimportant under the risk-neutral measure.

\subsection{Minimum Regulatory Capital}

The regulatory capital is the mandatory capital that the financial authorities specify. The banks' minimum regulatory capital requirements-Pillar I of the Basel II framework-are calculated as $8 \%$ of the risk weighed assets based on a formal set of detailed rules. The Basel II minimum regulatory capital will typically differ from the banks economic capital due to differences in model, data, and parameters although both measures of buffer capital aim at keeping the bank solvent in a worst case scenario based on a VaR methodology. Nevertheless, these differences between economic capital and minimum regulatory capital will typically be minimized as banks' internal economic capital figures are central to supervisors' assessment of regulatory capital adequacy under Pillar II of the 
Basel II framework. It must also be expected that differences between economic and regulatory capital will be further diminished as loopholes in Basel II will be closed by the forthcoming Basel III regulatory capital requirements. Therefore, we expect that the capital relief by introducing an APS can be based on the changes in economic capital.

For a portfolio without the APS, the minimum regulatory capital requirement $(\mathrm{CR})$ is

$$
C R^{\text {No APS }}=F \cdot R W_{1} \cdot 0.08,
$$

where $R W_{1}$ is the risk weight of the assets in the portfolio, and $F$ is the principal value. For a portfolio with an APS, this requirement is

$$
C R^{A P S}=\alpha_{1} \cdot F \cdot R W_{2} \cdot 0.08+\left(1-\alpha_{1}\right) \alpha_{2} \cdot F \cdot R W_{3} \cdot 0.08
$$

where $R W_{2}$ and $R W_{3}$ are risk weights for the equity tranche and for the retained fraction $\alpha_{2}$ of loss exceeding the first loss respectively.

For the minimum regulatory requirements to be reasonable, it should hold that $C R^{N o} A P S>C R^{A P S}$. The risk weights $R W_{1}, R W_{2}$, and $R W_{3}$, which are defined by the regulatory authorizes, determine whether entering an APS gives a minimum regulatory capital relief. Hence, we argue that these risk weights related to the APS should be specified in a meaningful manner.

\section{Conclusion}

We examine a specific portfolio credit derivative, an Asset Protection Scheme, and its applicability as a tool to restore financial stability and reduce asymmetric information. We consider the Danish agricultural sector as a case study and price an APS on an agricultural loan portfolio. Moreover, we compute the economic capital for this loan portfolio with and without the APS. With respect to credit modeling, we apply two alternative multivariate models within the structural credit risk framework; the classical Gaussian Merton model and a model based on Normal Inverse Gaussian processes.

We argue that that the APS can serve as a convenient tool to reduce asymmetric information and thereby help banks in raising new equity. As the financial crises demonstrated, especially in times of financial distress, it is crucial to be able to raise new equity capital. We find that the price for the Gaussian model is higher than for the NIG case due to the fact that the NIG model is able to match the positive skewness of the realized asset value returns. Finally, we find that the reduction in economic capital when introducing the APS is greater for the NIG model than the Gaussian case.

Of these two models, we suggest that the NIG is used for both risk management and pricing of the APS since this model is more flexible and able to describe extreme market risk. Furthermore, the economic capital numbers computed in 
our example indicate that the Gaussian model is not suitable since the economic capital increases after entering the APS.

\section{Acknowledgements}

We thank the Danish Agricultural Advisory Service (Landbrugsraadgivningen) for providing us the data set on Danish farms. We also thank Peter Løchte Jørgensen, Elisa Nicolato and David Skovmand for valuable comments. Furthermore, we are thankful to the participants at the Nordic Finance Network Workshop 2010 and the 14th International Congress on Insurance: Mathematics and Economics 2010 where the paper has been presented.

\section{References}

Akerlof, G., 1970. The market for "lemons": Quality uncertainty and the market mechanism. The Quarterly Journal of Economics 84 (3), 488-500.

Barndorff-Nielsen, O., 1997. Normal inverse Gaussian distributions and stochastic volatility modelling. Scandinavian Journal of Statistics 24 (1), 1-13.

Bartlett, M., 1950. Periodogram analysis and continuous spectra. Biometrika $37(1-2), 1$.

Bhattacharya, S., Thakor, A. V., 1993. Contemporary banking theory. Journal of Financial Intermediation 3 (1), 2-50.

Cont, R., Tankov, P., 2004. Financial Modelling with Jump Processes. Chapman \& Hall/CRC.

Cox, J., Ingersoll Jr, J., Ross, S., 1985. A theory of the term structure of interest rates. Econometrica 53 (2), 385-407.

Diamond, D. W., 1984. Financial intermediation and delegated monitoring. The Review of Economic Studies 51 (3), 393-414.

Jorion, P., 1997. Value at Risk. Irwin Homewood, IL.

Kalemanova, A., Schmid, B., Werner, R., 2007. The normal inverse Gaussian distribution for synthetic CDO pricing. The Journal of Derivatives 14 (3), 8094 .

Katchova, A. L., Barry, P. J., 2005. Credit risk models and agricultural lending. American Journal of Agricultural Economics 87 (1), 194-205.

Luciano, E., Schoutens, W., 2006. A multivariate jump-driven financial asset model. Quantitative Finance 6 (5), 385-402. 
Danmarks Nationalbank, Jun. 2009. Financial stability 2009, 1st half. Available from the Danmarks Nationalbank, www.nationalbanken.dk.

HM Treasury, Dec. 2009a. Royal Bank of Scotland: Details of asset protection scheme and launch of the asset protection agency. Available from www.hm-treasury.gov.uk.

HM Treasury, Feb. 2009b. UK asset protection scheme. Available from www.hmtreasury.gov.uk.

The Royal Bank of Scotland Group (RBS), Nov. 2009. The Royal Bank of Scotland Group plc (RBS) - Announcement on the APS and state aid discussions. Available from www.rbs.com.

US Department of Agriculture, Dec. 2009. 2007 census publications. The Census of Agriculture. Availabe from www.agcensus.usda.gov.

McNeil, A., Frey, R., Embrechts, P., 2005. Quantitative Risk Management: Concepts, Techniques, and Tools. Princeton University Press.

McNeil, A. J., Kirchner, A., Kretzschmar, G. L., 2008. The case for fully integrated models of economic capital. SSRN eLibrary.

Merton, R. C., 1974. On the pricing of corporate debt: The risk structure of interest rates. Journal of Finance 29 (2), 449-470.

Nicolato, E., Skovmand, D., 2010. Empirical analysis of affine LIBOR market models. Working Paper.

Pederson, G. D., Zech, L., 2009. Assessing credit risk in an agricultural loan portfolio. Canadian Journal of Agricultural Economics 57 (2), 169-185.

Raible, S., 2000. Lévy processes in finance: Theory, numerics, and empirical facts. University of Freiburg, Doctoral Thesis.

Repullo, R., Suarez, J., 2008. The procyclical effects of Basel II. SSRN eLibrary.

Rydberg, T., 1997. The normal inverse Gaussian Lévy process: Simulation and approximation. Stochastic Models 13 (4), 887-910.

Sherrick, B. J., Barry, P. J., Ellinger, P. N., 2000. Valuation of credit risk in agricultural mortgages. American Journal of Agricultural Economics 82 (1), 71-81.

Stokes, J. R., Brinch, B. M., 2001. Valuing agricultural mortage-backed securities. Journal of Agricultural and Applied Economics 33 (3), 493-511.

Yan, Y., Barry, P. J., 2006. Loss-given-default on farm real estate loans: Probability of full recovery. Agricultural Finance Review 66 (1), 47-59. 